\title{
Study on Soil Water and Suction Stress Characteristics for Unsaturated Clay Soil of Airport Engineering Based on Laboratory Tests
}

\author{
Jun Feng ${ }^{1}{ }^{1}$ and Guangze Zhang ${ }^{2}$ \\ ${ }^{1}$ School of Airport Engineering and Transportation Management, Civil Aviation Flight University of China, \\ Guanghan 618307, China \\ ${ }^{2}$ China Railway Eryuan Engineering Group.Co.Ltd, Chengdu 610031, China \\ Correspondence should be addressed to Jun Feng; sckid1987@163.com
}

Received 20 May 2021; Revised 23 June 2021; Accepted 7 July 2021; Published 23 July 2021

Academic Editor: Huie Chen

Copyright (c) 2021 Jun Feng and Guangze Zhang. This is an open access article distributed under the Creative Commons Attribution License, which permits unrestricted use, distribution, and reproduction in any medium, provided the original work is properly cited.

\begin{abstract}
For the unsaturated soil in Feidong China, this study examined the suction stress characteristics based on the soil-water characteristic curve (SWCC), which was different from traditional research ideas. At the same time, the unsaturated consolidation device was adopted for SWCC tests, with consideration of the influence of yielding stress of soil, which was different from the traditional test approach of the soil-water characteristic curve. The results were estimated using the van Genuchten model, which was revealed that this is well-fit for the studied unsaturated soil, and the triaxial shear-strength tests were conducted with suction control. Then, the suction stress characteristic curve (SSCC) was analyzed, and SWCC-predicted data were compared with triaxial test-derived suction stress data. For the studied unsaturated soil, the deviatoric stress increased with the net inner stress $\left(p-u_{a}\right)$ at the same matric suction. At the same net inner pressure, the deviatoric stress increased with the matric suction, which verified the hardening activity of matric suction on the tested unsaturated soil strength. Besides, triaxial test-derived suction stress data greatly conformed to SWCC data-derived SSCC that was determined using identical parameters used in the SWCC model.
\end{abstract}

\section{Introduction}

The soil-water characteristic and effective stress characteristic are the most important characteristics for unsaturated soil, which have an important influence on the mechanical behavior of unsaturated soil. The soil-water characteristic could be described by soil-water characteristic curve (SWCC), and the effective stress characteristic could be described by the suction stress characteristic curve (SSCC) [1-2]. In addition, the SSCC defines the distribution of stresses that act between the solid particles and the pore fluid in soils, which is very important in unsaturated soil mechanics. Alfrendo et al. [3] put forward a formula for predicting soil SWCC that showed bimodal features, and they were tightly associated with soil physical features and SWCC var- iables [3]. Shao et al. [4] carried out four sets of suctioncontrolled tests, and the influence of the matric suction and intermediate principal stress parameter were analyzed [4]. I.D.Akin et al. [5] studied the suction stress characteristic of compacted kaolinite clay soil with considering a wide range of saturation [5]. Wang et al. [6] were the first to propose a method to derive suction stress characteristic curve by the use of the intermediate liquid bridge model [6]. Dong et al. (2021) established the SSCC after taking SWCC into consideration under the high-suction stress condition [7]. The present work investigated those soil-water curve features by the use of suction stress and yield stress curves in the presence of diverse stresses by laboratory tests for unsaturated clay soil of airport engineering in the Hefei area, and then, the engineering mechanical properties of the soil were analyzed. 


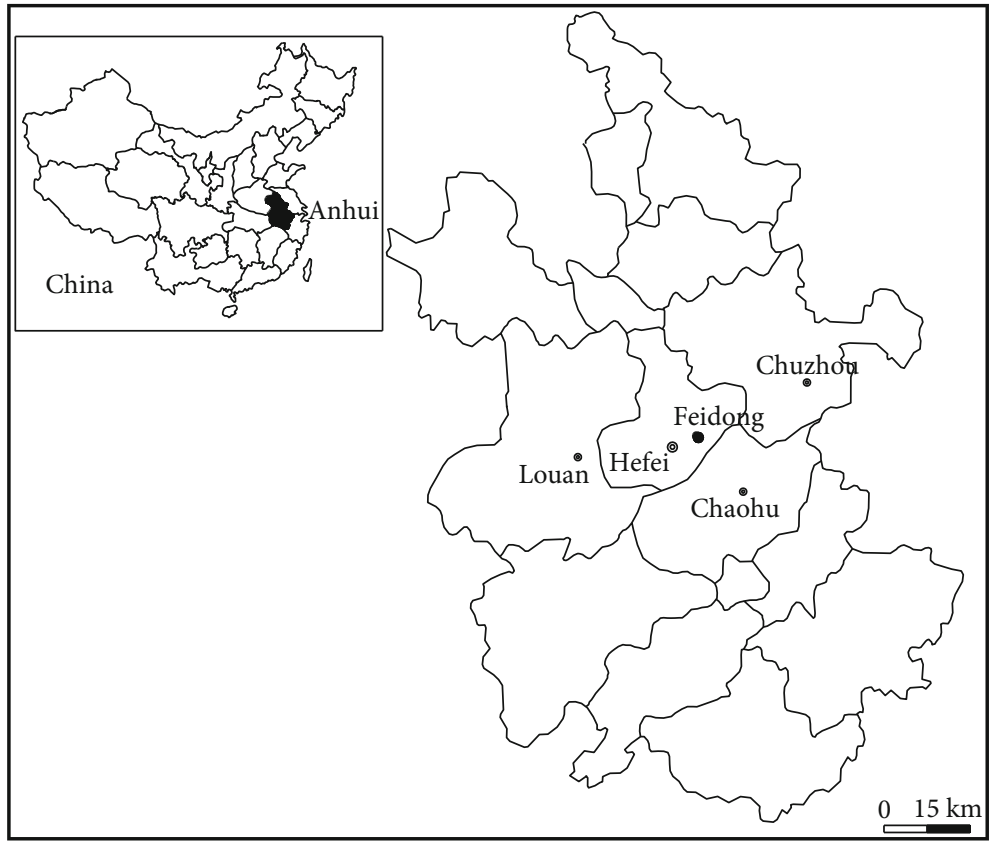

FIGURE 1: Location of the unsaturated soils tested in the present study.

TABle 1: Physical properties of the soil obtained from Feidong.

\begin{tabular}{lccccccc}
\hline Sample & Liquid limit (\%) & Plastic limit (\%) & Plasticity index (\%) & $\begin{array}{c}\text { Free swelling } \\
\text { ratio (\%) }\end{array}$ & Specific gravity & $\begin{array}{c}\text { Initial water } \\
\text { content (\%) }\end{array}$ & $\begin{array}{l}\text { Void ratio } \\
\text { Feidong clay }\end{array}$ \\
\hline & 37.8 & 24.8 & 13 & 45 & 2.73 & 19.26 \\
\hline
\end{tabular}

\section{Experimental Program}

\subsection{The SWCC Program}

2.1.1. Test Preparation. Since the 1990s, SWCC exerts a more and more important effect on unsaturated soil research, and a number of researchers have focused on the SWCC test. Liu et al. [8] used the Temper apparatus for measuring matric suction and calculating the SWCC [8]. Mao et al. [9] investigated the SWCC for unsaturated soil based on the technical of dialysis [9]. Shen et al. [10] utilized the salt solution method to obtain the SWCC for unsaturated soil [10]. Nam [11] used 6 distinct approaches for establishing SWCC, such as dewpoint potentiometer, filter paper, pressure plate, vapor equilibrium, osmotic, or Tempe cell approach, suggesting that every suction measuring method offers diverse suction measuring ranges [11]. However, these methods for obtaining the SWCC cannot reflect the influences of net vertical stress, which play an important role in influencing the consolidation and mechanic characteristics of unsaturated soil. A number of researches have verified the yielding stress, which can reflect the yielding characteristics of soil to stress. Hence, analyzing unsaturated soil SWCC is of vital importance when the net vertical stress comes to the yielding stress. Hence, yielding stress was initially obtained for the studied soil, and the SWCC test was subsequently operated by the unsaturated soil consolidation apparatus in the present study.

In the present study, Hefei soil, which is the representative unsaturated soil in China, was used as the soil sample.

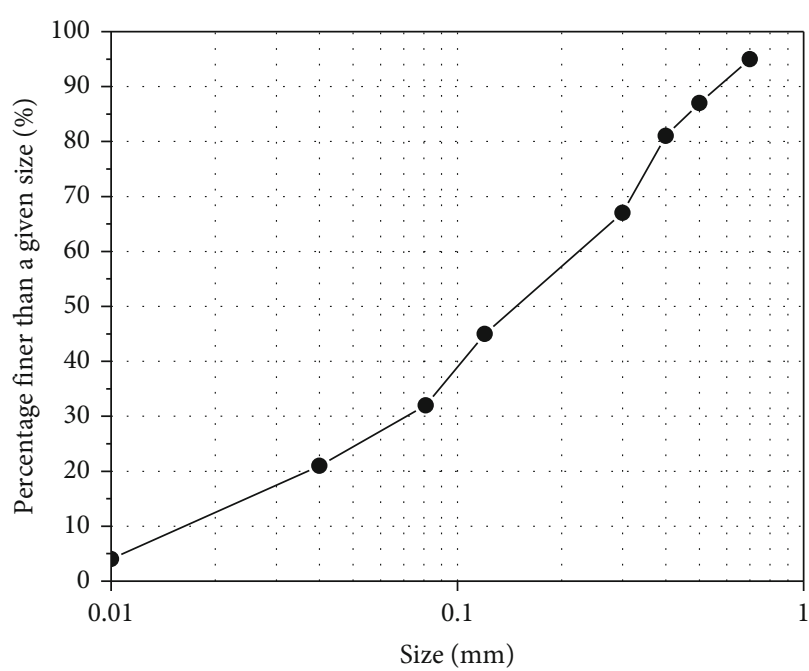

FIGURE 2: Grain-size distribution curve for the studied soil obtained from Feidong.

The location for the tested soils was Feidong county (Figure 1).

Table 1 shows the soil physical properties. Figure 2 displays the curve regarding soil grain-size distribution. Based on Modified Standard Proctor Compaction test results, the maximal dry density $\rho_{d \text {, max }}$ was determined to be $1.59 \mathrm{~g} / \mathrm{cm}^{3}$ under the optimal water content of $21.8 \%$. 
TABLE 2: Basic physical and mechanical properties of the soil samples.

\begin{tabular}{|c|c|c|c|c|c|}
\hline Number & $\begin{array}{c}\text { Depth of soil sample } \\
m\end{array}$ & $\begin{array}{l}\text { Specific gravity of soil particle } \\
\qquad G_{s}\end{array}$ & $\begin{array}{c}\text { Initial dry density } \\
\rho_{d} / \mathrm{g} / \mathrm{cm}^{3}\end{array}$ & $\begin{array}{c}\text { Initial water content } \\
w_{0} / \% \\
\end{array}$ & $\begin{array}{c}\text { Initial void ratio } \\
e_{0} \\
\end{array}$ \\
\hline (1) & 0 & 2.73 & 1.74 & 19.05 & 0.57 \\
\hline (2) & 4 & 2.72 & 1.74 & 19.10 & 0.56 \\
\hline (3) & 8 & 2.73 & 1.74 & 19.10 & 0.57 \\
\hline (4) & 12 & 2.73 & 1.74 & 19.05 & 0.57 \\
\hline
\end{tabular}

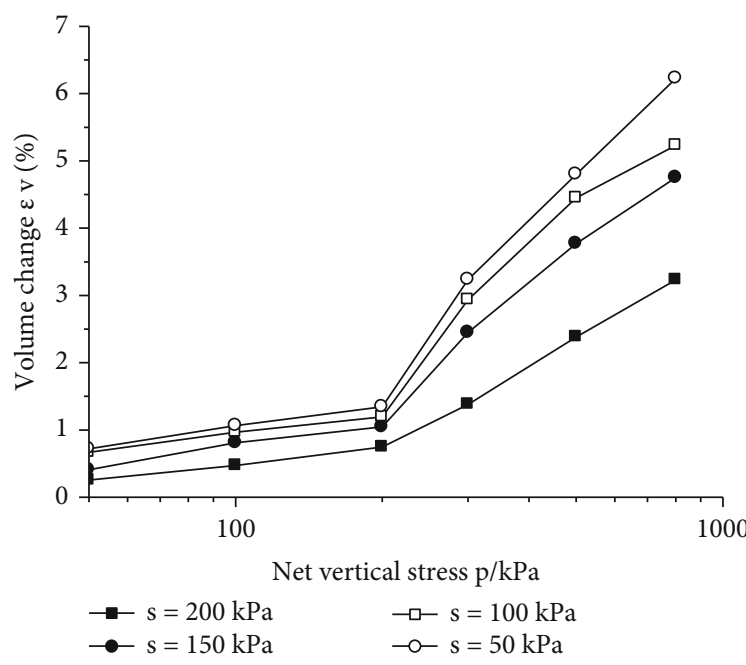

(a) Soil sample (1)

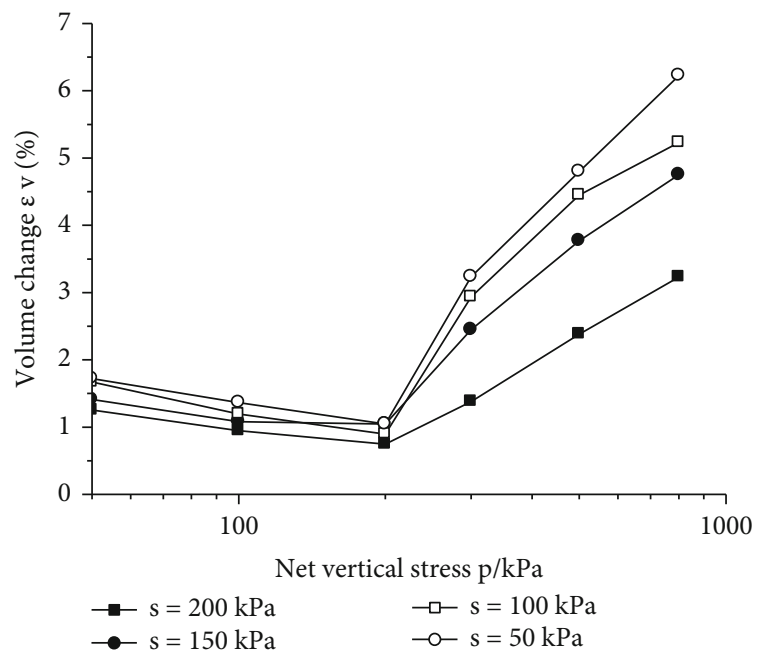

(c) Soil sample (3)

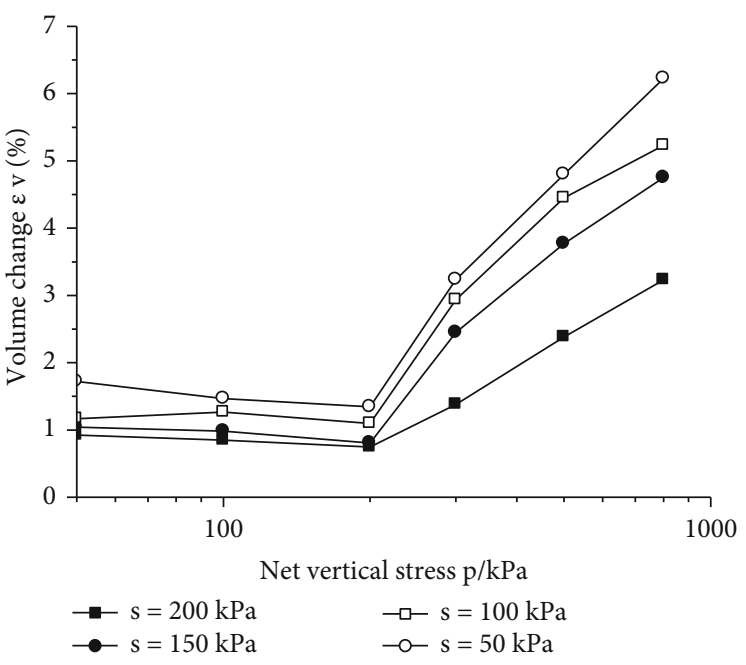

(b) Soil sample (2)

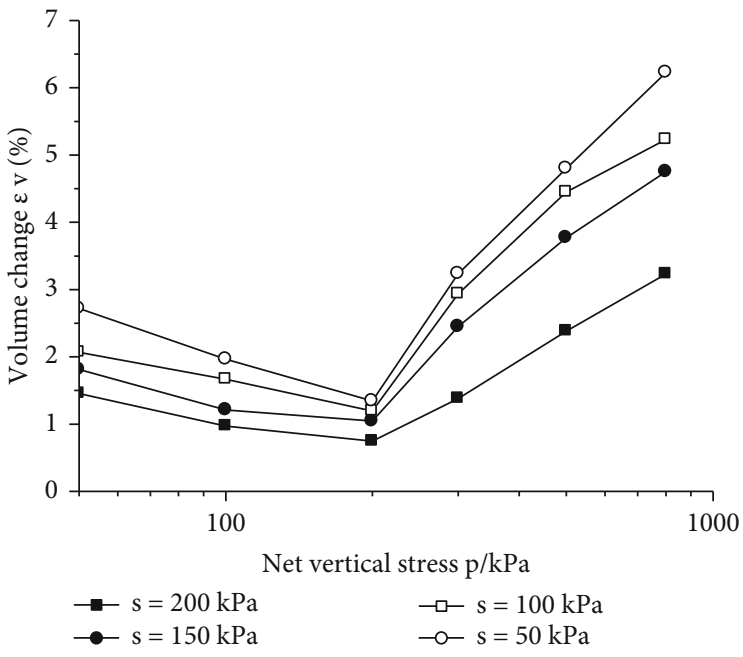

(d) Soil sample (4)

Figure 3: The $\varepsilon_{v} \sim \lg p$ curves at different matric suctions.

2.1.2. Determination of Yielding Stress. In the study area, soils in four kinds of depth were selected for the test, in order to determine the yielding stress. The depths were $0,4,8$, and $12 \mathrm{~m}$, respectively, in the same location nearby a railway in Feidong county. The yielding stress was determined using the matric suction-controlled tests, where each soil sample was subjected to a net vertical stress. The unsaturated soil consolidation apparatus was adopted for the tests. The undisturbed soil samples at each depth were processed into the sample ring, and the height and inside diameter were 20 and $61.8 \mathrm{~mm}$, respectively. Table 2 exhibits original soil physical properties. The suctions adopted for the tests were 50, 100,150 , and $200 \mathrm{kPa}$, respectively (engineering practices have verified that the overwhelming majority of geotechnical problems was within the range of the suction) [12-17]. The net vertical stresses used were 50,100, 200, 300, 500, and $800 \mathrm{kPa}$, respectively.

The logarithmic relationship curves $\varepsilon_{v} \sim \lg p$ of the tested soil samples obtained from the laboratory tests are shown in Figure 3 . 


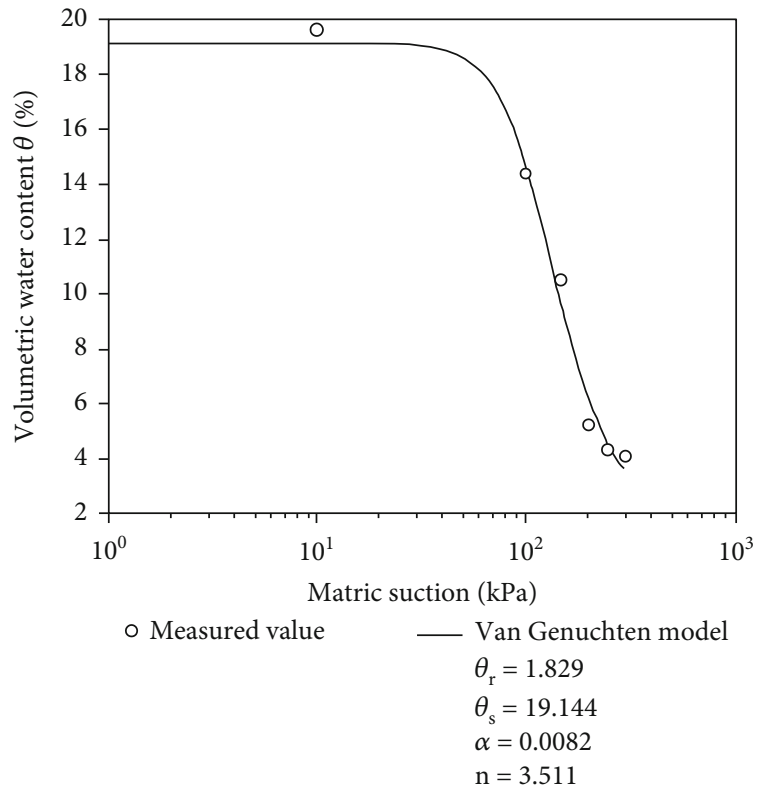

Figure 4: The SWCC for the compacted Feidong soil.

Based on the method of Chen [18] and Alonso et al. [19] for determining the yielding suction, the present study took the inflection point of the $\varepsilon_{v} \sim \lg p$ curve as the yielding point of vertical stress [18-19]. As shown in Figure 4, the yielding stress of each sample was approximately $200 \mathrm{kPa}$. Hence, for the studied unsaturated soil of Feidong, this adopted a yielding stress of $200 \mathrm{kPa}$.

2.1.3. Test and Results. Considering the influence of yielding stress, SWCC tests were conducted for the studied unsaturated soil using the unsaturated soil consolidation apparatus, and the net vertical stress was controlled at a yielding stress of $200 \mathrm{kPa}$. The specimens for the SWCC were also processed into the sample ring, whose height and inside diameter were 20 and $61.8 \mathrm{~mm}$, respectively. The stable water content of soil samples with different suctions can be calculated using the water displacement and initial water content. Volumetric water content was determined based on the formula $\theta=\omega$ $G_{s} / 1+e$, (where $\theta$ refers to the volumetric water content, $\omega$ refers to the quality water content, $G_{s}$ refers to the specific gravity, and $e$ refers to the void ratio), whereas SWCC was described based on the association of matric suction with volumetric water content. There are a number of empirical models to describe the SWCC. In general, there are 4 commonly utilized empirical ones, including Gardner, BroodsCorey, Gardner-Russo, and Van-Genuchten models. The van Genuchten model is the most popular empirical model for fitting the SWCC. This was proposed by van Genuchten in 1980, which adopted the association of efficient saturation level with pressure head according to the initial Mualem's equation (1976) [20]. At the same time, Song and colleagues (2010) assessed those welcome SWCC models. According to their results, van Genuchten (1980) model represented the optimal method for estimating SWCC for the test material Jumoonjin Standard Sanf [21].
Therefore, in the present study, the SWCC was estimated through van Genuchten's equation (1980) by adopting water flow and matric suction results. Besides, the association of volumetric water content with matric suction was determined by nonlinear least-squares regression for the sake of obtaining those van Genuchten (1980) model-related curvefitting parameters. This is shown in Figure 4.

Figure 4 presents the SWCC for the studied unsaturated soil, with consideration of the influence of yielding stress and the fitting curve with the van Genuchten model, and the fitting correlation parameter $R^{2}=0.97$. This revealed that the van Genuchten model can well fit the unsaturated soil. The fitting parameters are presented in Figure 4.

\subsection{The SSCC Program}

2.2.1. Test Preparation. For the studied unsaturated soil in Feidong, triaxial tests were conducted to obtain the SSCC at different matric suctions. Furthermore, the strength characteristic of the unsaturated soil in different matric suctions was analyzed. This study conducted triaxial tests by the use of the unsaturated soil triaxial test device. In the tests, the suction and net inner pressure were controlled together. The soil tested in the program was obtained from the same location near the same railway in Feidong county. The results analyzed by the X-ray diffraction test revealed that the main clay mineral of the soil was montmorillonite $(20.3 \%)$ and illite $(15.2 \%)$, and the one-dimensional free expansion rate was $16 \%$. This belongs to the midexpansive soil, according to the expansive soil classification standards of China's water conservancy department. The initial moisture content of the soil was $18.2 \%$.

The specimens were prepared using the static method. The test was performed in strict accordance with the Railway Engineering Geotechnical Test Specification (TB101022004). Initially, the soil samples obtained at different depths are made into cylinders, whose height and diameter were 76 and $38 \mathrm{~mm}$, respectively. Following sample cutting, we used the Vernier caliper to measure its height and diameter, the weight was measured using an electronic scale, and the density was calculated. Finally, we utilized an oven to measure soil moisture content. The saturated samples were saturated with a vacuum saturator, and after the triaxial shear apparatus was installed, we conducted triaxial tests. The triaxial test for the unsaturated soil consisted of three stages: suction equilibrium, equal suction consolidation, and shear. A good sample preparation is often different from the initial suction test set of the suction value (that is, the stage of consolidation and shear), in order to control the suction. The suction balance is the change in suction in the soil sample, and this was induced to reach the set value. At the end of this phase, a slowly increasing confining pressure was maintained for the suction to test the set of consolidation pressures and control the suction. The consolidation time ensured to be long enough for the shear rate to be slower. With reference to existing experience, shear rate control was set at $0.0125 \mathrm{~mm} / \mathrm{min}$. Four groups of suction constants were adopted: 0, 50, 100, and $200 \mathrm{kPa}$. The net inner pressures were controlled at 100 , 200, 300, and $400 \mathrm{kPa}$. Table 3 displays the test plan. The 
TABLE 3: Scheme for the triaxial tests.

\begin{tabular}{|c|c|c|c|c|c|}
\hline Sample number & Initial water content (\%) & Initial density $\left(\mathrm{g} / \mathrm{cm}^{3}\right)$ & Type of test & Matric suction $(\mathrm{kPa})$ & Net inner pressure $(\mathrm{kPa})$ \\
\hline Feidong 1 & 16.95 & 2.07 & \multirow{4}{*}{$\begin{array}{l}\text { Consolidation } \\
\text { drained shear tests } \\
\text { for saturated } \\
\text { specimen }\end{array}$} & \multirow{4}{*}{0} & 100 \\
\hline Feidong 2 & 16.95 & 2.07 & & & 200 \\
\hline Feidong 3 & 16.95 & 2.07 & & & 300 \\
\hline Feidong 4 & 16.94 & 1.98 & & & 400 \\
\hline Feidong 5 & 21.82 & 1.94 & \multirow{4}{*}{$\begin{array}{c}\text { Consolidation } \\
\text { drained shear tests } \\
\text { for unsaturated } \\
\text { specimen }\end{array}$} & \multirow{4}{*}{50} & 100 \\
\hline Feidong 6 & 21.82 & 1.94 & & & 200 \\
\hline Feidong 7 & 21.82 & 1.945 & & & 300 \\
\hline Feidong 8 & 21.82 & 1.94 & & & 400 \\
\hline Feidong 9 & 24.07 & 2.01 & \multirow{4}{*}{$\begin{array}{c}\text { Consolidation } \\
\text { drained shear tests } \\
\text { for unsaturated } \\
\text { specimen }\end{array}$} & \multirow{4}{*}{100} & 100 \\
\hline Feidong 10 & 24.05 & 1.99 & & & 200 \\
\hline Feidong 11 & 24.05 & 1.98 & & & 300 \\
\hline Feidong 12 & 24.08 & 2.01 & & & 400 \\
\hline Feidong 13 & 20.78 & 2.01 & \multirow{4}{*}{$\begin{array}{l}\text { Consolidation } \\
\text { drained shear tests } \\
\text { for unsaturated } \\
\text { specimen }\end{array}$} & \multirow{4}{*}{200} & 100 \\
\hline Feidong 14 & 19.82 & 1.96 & & & 200 \\
\hline Feidong 15 & 19.82 & 1.95 & & & 300 \\
\hline Feidong 16 & 19.83 & 1.97 & & & 400 \\
\hline
\end{tabular}

standard for stability in the tests is, as follows: the volume change was less than $0.006 \mathrm{~cm}^{3}$, and the drainage discharge was less than $0.012 \mathrm{~cm}^{3}$ within two hours. Each test required three days, including the consolidation stage for two days, and the shear stage for one day. For unsaturated soil, we set tests with $0 \mathrm{kPa}$ suction (saturated soil) as control.

\subsubsection{Test Results}

(1) The Relationships between Deviatoric Stress and Deviatoric Strain. The graphs for the deviator stress and deviator strain at different suctions are shown in Figure 5.

Figure 5 displays the association of deviatoric strain with deviatoric stress at different matric suctions. The curve under the net inner stress of $200 \mathrm{kPa}$ in Figure 5(c) is abnormal, because of the data was not recorded in time in the actual experiment, which did not affect the change rule of the whole relationship. Clearly, as the deviatoric strain increased, deviatoric stress showed an increasing trend at the beginning and, subsequently, remained stable at the studied range of matric suction. For the studied unsaturated soil, the deviatoric stress increased with the net inner stress $\left(p-u_{a}\right)$ at the same matric suction. In the same net inner pressure, the deviatoric stress increased with the matric suction, suggesting the hardening activity of matric suction for the strength characteristic of the studied unsaturated soil. The strength parameters of the triaxial tests are shown in Table 2. The $p_{f}$ and $q_{f}$ are the net mean mass and deviatoric stress under the state of failure. This can be calculated using the following formula:

$$
p=\frac{\sigma_{1}+\sigma_{2}+\sigma_{3}}{3}-u_{a}, q=\sigma_{1}-\sigma_{3}
$$

where $\sigma_{1}, \sigma_{2}$, and $\sigma_{3}$ represents the three principal stresses, which can be calculated through the triaxial tests.
In addition, the relationship between $p$ and $q$ can be described in Figure 6 . In the $p-q$ plane, the relationship can be fitted using the following formula:

$$
p=\xi+q \cdot \operatorname{tg} \omega
$$

where $\xi$ and $\operatorname{tg} \omega$ represent the interception and slope of the fitting line. These can be calculated using the least square method. The $\varphi^{\prime}$ and $c^{\prime}$ represent the internal friction angle and cohesive force for unsaturated soil. The calculation results of each parameter are shown in Table 4.

(2) Estimation of the SSCC. During triaxial tests, the failure criterion can be defined by the effective stress, in terms of $p$ ' and $q$, as follows:

$$
\begin{aligned}
\phi^{\prime} & =\sin ^{-1}[3 M /(6+M)], \\
c^{\prime} & =\frac{d}{M} \tan \phi^{\prime}, \\
q_{f} & =d+M p_{f}^{\prime}, \\
q_{f} & =d+M\left(p-u_{a}\right)_{f}-M \sigma^{s},
\end{aligned}
$$

where for the $\left(p-u_{a}\right)-q$ space, $c$ represents the slope of the failure envelope and $d$ represents the intersection of the failure envelope at full saturation. The subscript $f$ represents the state of failure. In the triaxial tests, the saturated friction angle and cohesion can be derived from $M$ and $d . \sigma^{s}$ represents the suction stress, as a function of matric suction, can be quantified from the triaxial tests. $\sigma^{s}$ can be described as formula (4). Based on the experimental results in Table 4 and the relevant theories of effective stress, the corresponding suction stress values could be calculated according to the following formula (4). Based on the theory of suction stress 


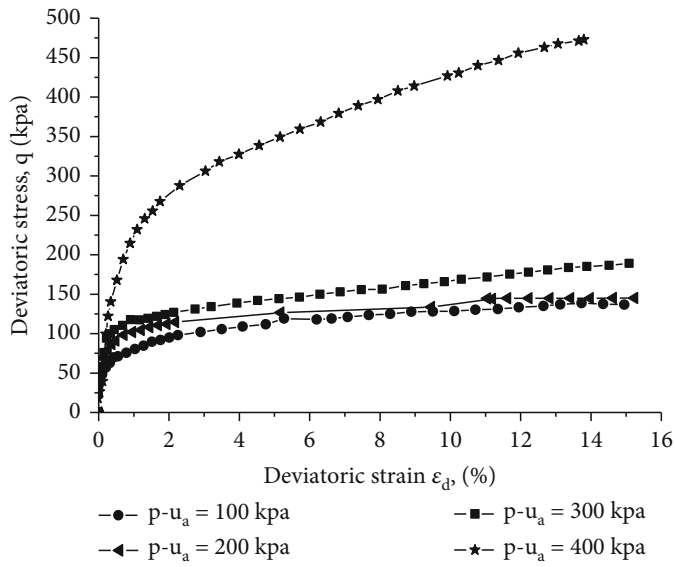

(a) Matric suction $=0 \mathrm{kPa}$

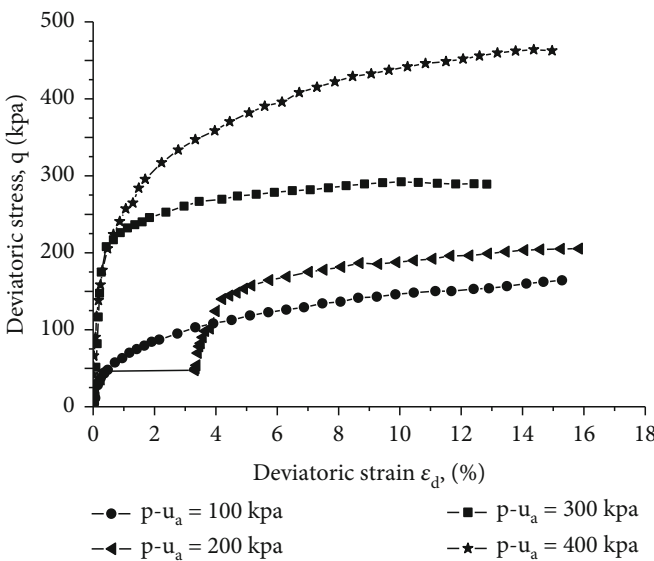

(c) Matric suction $=100 \mathrm{kPa}$

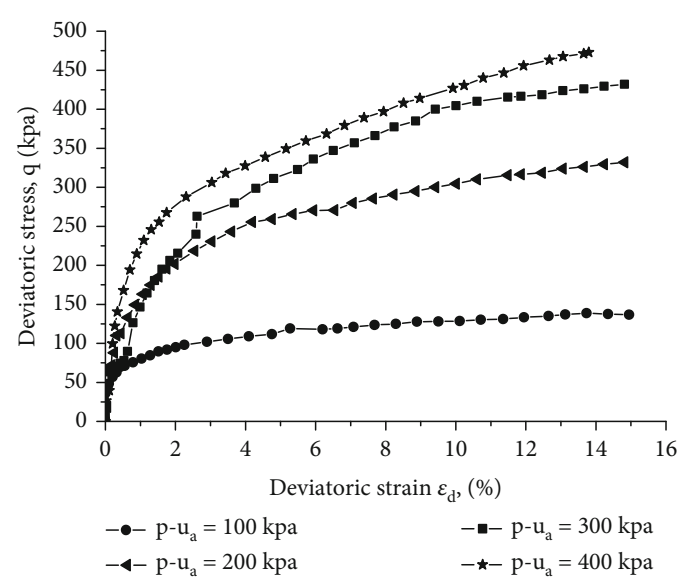

(b) Matric suction $=50 \mathrm{kPa}$

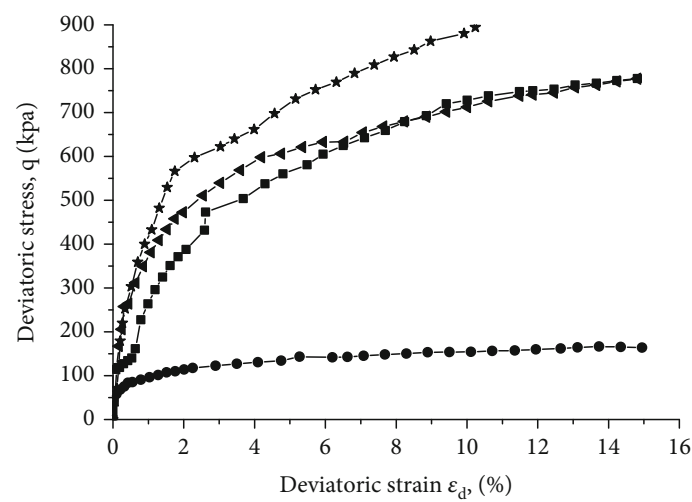

$\begin{array}{ll}-\bullet-\mathrm{p}-\mathrm{u}_{\mathrm{a}}=100 \mathrm{kpa} & -\bullet-\mathrm{p}-\mathrm{u}_{\mathrm{a}}=300 \mathrm{kpa} \\ -4-\mathrm{p}-\mathrm{u}_{\mathrm{a}}=200 \mathrm{kpa} & -\star-\mathrm{p}-\mathrm{u}_{\mathrm{a}}=400 \mathrm{kpa}\end{array}$

(d) Matric suction $=200 \mathrm{kPa}$

FIgURE 5: The relationships between deviatoric stress and deviatoric strain with different matric suctions.

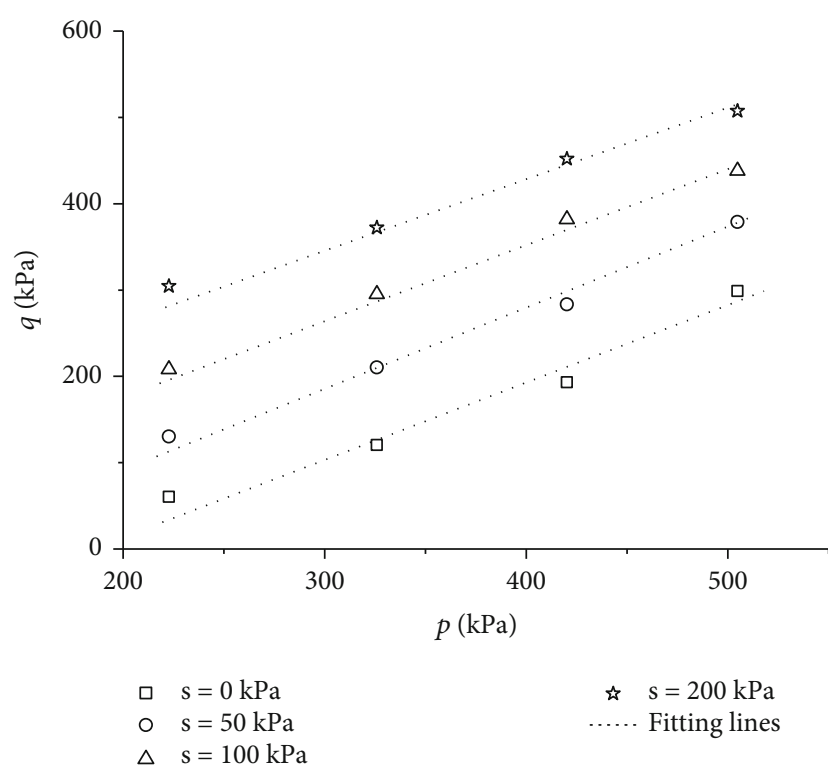

Figure 6: The strength envelope in the $p-q$ plane (SSCC).
TABLE 4: Strength parameters of the triaxial tests.

\begin{tabular}{|c|c|c|c|c|c|c|c|}
\hline $\begin{array}{l}\text { Matric } \\
\text { suction } \\
(\mathrm{kPa}) \\
\end{array}$ & $\begin{array}{c}\text { Net inner } \\
\text { pressure } \\
(\mathrm{kPa})\end{array}$ & $\begin{array}{c}q_{f} \\
(\mathrm{kPa})\end{array}$ & $\begin{array}{c}p_{f} \\
(\mathrm{kPa})\end{array}$ & $\begin{array}{c}\xi \\
(\mathrm{kPa})\end{array}$ & $\operatorname{tg} \omega$ & $\begin{array}{c}c^{\prime} \\
(\mathrm{kPa})\end{array}$ & $\begin{array}{l}\phi^{\prime} \\
(\circ)\end{array}$ \\
\hline \multirow{4}{*}{0} & 100 & 60.23 & 180.54 & \multirow{4}{*}{7.4} & \multirow{4}{*}{1.32} & \multirow{4}{*}{3.8} & \multirow{4}{*}{18.5} \\
\hline & 200 & 120.42 & 214.43 & & & & \\
\hline & 300 & 193.15 & 307.92 & & & & \\
\hline & 400 & 298.89 & 528.33 & & & & \\
\hline \multirow{4}{*}{50} & 100 & 130.23 & 200.54 & \multirow{4}{*}{35.24} & \multirow{4}{*}{0.66} & \multirow{4}{*}{45} & \multirow{4}{*}{17.35} \\
\hline & 200 & 210.42 & 254.43 & & & & \\
\hline & 300 & 283.15 & 347.92 & & & & \\
\hline & 400 & 378.89 & 568.33 & & & & \\
\hline \multirow{4}{*}{100} & 100 & 208.12 & 221.65 & \multirow{4}{*}{127.49} & \multirow{4}{*}{0.69} & \multirow{4}{*}{60.12} & \multirow{4}{*}{17.91} \\
\hline & 200 & 295.11 & 315.13 & & & & \\
\hline & 300 & 382 & 451.99 & & & & \\
\hline & 400 & 438.15 & 484.22 & & & & \\
\hline \multirow{4}{*}{200} & 100 & 304.35 & 222.78 & \multirow{4}{*}{178.09} & \multirow{4}{*}{0.65} & \multirow{4}{*}{84.04} & \multirow{4}{*}{17.96} \\
\hline & 200 & 372.14 & 325.9 & & & & \\
\hline & 300 & 452.01 & 420.12 & & & & \\
\hline & 400 & 507.42 & 504.85 & & & & \\
\hline
\end{tabular}




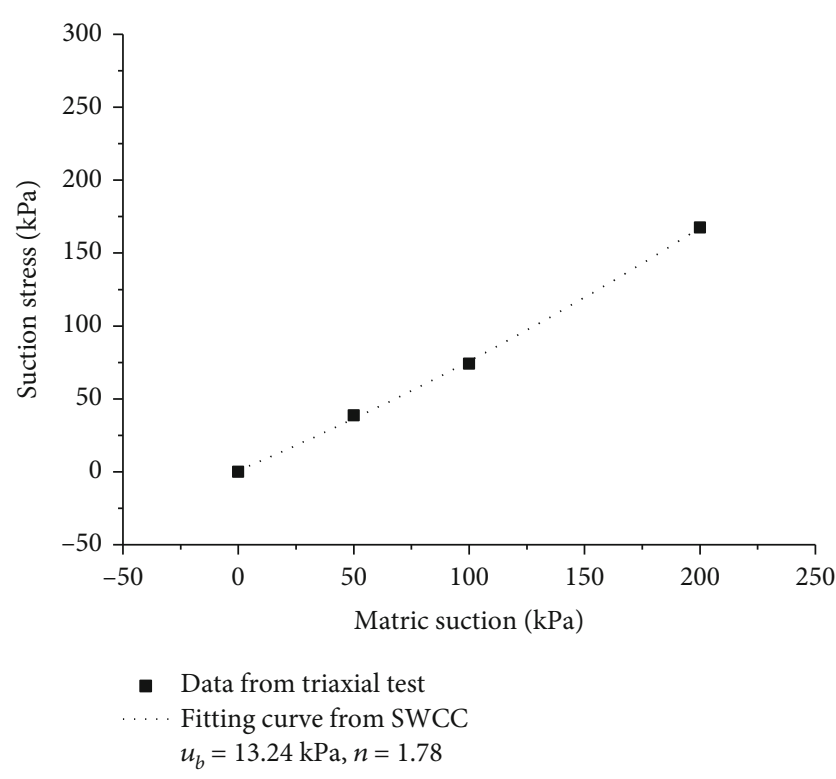

Figure 7: The relationship between matric suction and suction stress.

and matric suction, which could be described in formula (5). The relationship between suction stress and matric suction was shown in Figure 7. In Figure 7, the $u_{b}$ represents the air-entry pressure, and $n$ represents the pore-size spectrum number.

$$
\begin{aligned}
& \sigma^{s}=\frac{d+M\left(p-u_{a}\right)_{f}-q_{f}}{M}, \\
& \sigma^{s}=-\left(u_{a}-u_{w}\right) \theta_{e},
\end{aligned}
$$

where $\theta_{e}$ represents the effective volumetric water content.

Least squares regression was utilized for fitting shearstrength data to Equation (4), for the sake of calculating SSCC. To make it convenient for comparison, we chose the identical value of parameter $\alpha$ (or $u_{b}$ ) to that acquired based on SWCC fitting, whereas $n$ as the only parameter assessed by triaxial tests to compare the results. Figure 7 shows those parameters assessed for SSCCs and SWCC based on triaxial shear-strength and soil-water retention tests.

\section{Conclusions}

In the present study, two kinds of experiments were conducted for the studied soil: the SWCC test and the triaxial test. In the SWCC test, the unsaturated consolidation apparatus was used, in consideration of the influence of yielding stress. The van Genuchten (1980) model was adopted to estimate the results, and it was well fitted with the evaluated unsaturated soil. The SSCC was obtained and estimated using the formula proposed by Lu and Likos (2006). In addition, SSCC was compared between triaxial test-derived suction stress data and SWCC estimated data. This was obtained, as follows:
(1) Deviatoric stress showed an increasing trend as deviatoric strain elevated at first and, subsequently, remained stable at the studied range of matric suction. For the studied unsaturated soil, the deviatoric stress increased with the net inner stress $\left(p-u_{a}\right)$ at the same matric suction. With the same net inner pressure, the deviatoric stress increased with the matric suction. This verifies the hardening activity of matric suction for strength characteristic of the studied unsaturated soil

(2) Triaxial test-obtained suction stress data were well fitted with SWCC-derived SSCC data. After measuring SWCC, we determined SSCC using identical parameters from the SWCC model. Based on our experimental results, SWCC was correlated with SSCC. As a result, stress distribution and seepage issues might be assessed directly by the soil-water retention test. When the obtained SWCC represents a soil, we may avoid the time-consuming and complex shear-strength tests in the unsaturated environment. The above findings are of great theoretical importance to construct unsaturated soil foundations

\section{Data Availability}

The figures presenting the test data analysis were all drawn in Origin 8.0. The data are available and explained in this article. Readers can access the data supporting the conclusions of this study. Also, all the data files used to support the findings of this study are available from the corresponding author upon request.

\section{Conflicts of Interest}

The authors declare that they have no conflicts of interest.

\section{References}

[1] T. M. Thu, H. Rahardjo, and E. C. Leong, "Elastoplastic model for unsaturated soil with incorporation of the soil-water characteristic curve," Canadian Geotechnical Journal, vol. 44, no. 1, pp. 67-77, 2007.

[2] Q. Zhai and H. Rahardjo, "Determination of soil-water characteristic curve variables," Computers and Geotechnics, vol. 42, pp. 37-43, 2012.

[3] A. Satyanaga, H. Rahardjo, E. C. Leong, and J. Y. Wang, "Water characteristic curve of soil with bimodal grain-size distribution," Computers and Geotechnics, vol. 48, pp. 51-61, 2013.

[4] S. Shao, S. Shao, and J. Wang, "True triaxial mechanical properties of unsaturated loess in foundation pit engineering," Bulletin of Engineering Geology and the Environment., vol. 80, no. 6, pp. 4751-4772, 2021.

[5] I. D. Akin and W. J. Likos, "Suction stress of clay over a wide range of saturation," Geotechnical and Geological Engineering., vol. 38, no. 1, pp. 283-296, 2020.

[6] X. L. Wang, Z. Zhang, J. C. Li, and Q. Liu, "Mesoscale analysis of the suction stress characteristic curve for unsaturated granular materials," Particuology, vol. 56, pp. 183-192, 2021. 
[7] Y. Dong and N. Lu, "Measurement of suction stress and soil deformation at high suction range," Geotechnical Testing Journal., vol. 44, no. 2, p. 20190357, 2021.

[8] X. M. Liu, H. L. Zhao, and L. J. Wang, "Research on soil-water character of unsaturated pulverescent clay by experiment," Journal of Shi Jiazhuang Railly Institute, vol. 14, no. 3, pp. 78-82, 2001.

[9] S. L. Mao, "A study on soil-water characteristic curve of unsaturated soil," Journal of Engineering Geology, vol. 10, no. 2, pp. 129-133, 2002.

[10] Z. Y. Shen, G. D. Li, and S. S. Li, "Determination of moisture curve of highly compacted bentonite," Geotichnical Investigation and Surveying, vol. 4, pp. 27-28, 1998.

[11] S. Nam, M. Gutierrez, P. Diplas et al., "Comparison of testing techniques and models for establishing the SWCC of riverbank soils," Engineering Geology, vol. 110, no. 1-2, pp. 1-10, 2010.

[12] W. X. Su and K. H. Xie, "Calculation of one-dimensional consolidation of unsaturated soil with straight-line soil-water characteristic curve," Journal of Zhejiang University, vol. 44, no. 1, pp. 150-155, 2010.

[13] W. M. Ye, Y. Bai, Q. Jin, B. Chen, and Y. J. Cui, "Experimental study on soil-water characteristics of soft soils in Shanghai," Chinese Journal of Geotechnical Engineering, vol. 2, pp. 260263, 2006.

[14] J. Lu and B. Cheng, "Study on soil-water characteristic curve of unsaturated loess," Chinese Journal of Geotechnical Engineering, vol. 10, pp. 1591-1592, 2007.

[15] D. G. Fredlund and A. Xing, "Erratum: equations for the soilwater characteristic curve," Canadian Geotechnical Journal, vol. 31, no. 6, pp. 1026-1026, 1994.

[16] J. T. Stoicescu, M. D. Haug, and D. G. Fredlund, “The soilwater characteristics and pore size distribution of a sandbentonite mixture," in Proceeding of the 49th Canadian Geotechnical Conference, pp. 721-728, Newfoundland, Canada, 1996.

[17] S. S. Agus, E. C. Leong, and H. Rahardjo, "Soil-water characteristic curves of Singapore residual soils," Geotechnical and Geological Engineering, vol. 19, no. 3/4, pp. 285-309, 2001.

[18] Z. H. Chen, "Deformation, strength, yield and moisture change of a remolded unsaturated loess," Chinese Journal of Geotechnical Engineering, vol. 21, no. 1, pp. 82-90, 1999.

[19] E. E. Alonso, A. Gens, and A. A. Josa, "A constitutive model for partially saturated soils," Geotechnique, vol. 40, no. 3, pp. 405430, 1990

[20] Y. Mualem, "A new model for predicting the hydraulic conductivity of unsaturated porous media," Water Resources Research., vol. 12, no. 3, pp. 513-522, 1976.

[21] Y.-S. Song, H. Woong Ki, and T.-H. Kim, "Construction and application of an automated apparatus for calculating the soil-water characteristic curve," The journal of Engineering Geology, vol. 20, no. 3, pp. 281-295, 2010. 